\title{
EDUCAÇÃO DE PROFESSORES DA UNIVERSIDADE NO CONTEXTO DE INTERAÇÃO UNIVERSIDADE-ESCOLA
}

\section{Education of university professors in the context of university-school interaction}

\author{
Zulind Luzmarina Freitas ${ }^{1}$. Lizete Maria Orquiza de Carvalho² ${ }^{2}$ \\ Ernandes Rocha de Oliveira ${ }^{3}$
}

Resumo: Este artigo apresenta resultados de uma pesquisa sobre a formação de professores da universidade que atuam em licenciaturas de Física, Biologia e Matemática, procurando compreendê-la a partir de sua participação em um projeto de formação continuada de professores da rede pública de ensino. $\mathrm{O}$ referencial teórico, apoiado em Pierre Bourdieu e Paulo Freire, possibilitou a constituição de instrumentos para caracterizar o processo de formação como construção coletiva de uma estrutura formativa. Para isso, foi necessário considerar tanto a interação de professores da universidade entre si como aquela entre eles e os professores da escola. Os resultados revelaram que o envolvimento dos professores da universidade no projeto possibilitou-lhes a produção de conhecimento em um domínio para o qual normalmente não são chamados a fazê-lo, na prática da vida universitária, a saber: a docência.

Palavras-chave: Formação de professores. Formação de formadores.

\begin{abstract}
This article presents results of research on education of university professors who work in Undergraduate Physics, Biology and Mathematics Education Courses, starting from their participation in a project of continuing education for public school teachers. The theoretical framework, supported by Pierre Bourdieu and Paulo Freire, allowed us to construct instruments in order to characterize the education process as a collective construction of a formative endeavor. For this purpose, it was necessary to consider both the interaction among university teachers and the interaction among them and the high school teachers. The research results show that the involvement of university teachers in the project enabled them to produce knowledge in a domain that they are not normally called to do it, in the practice of everyday university life, namely, the teaching.
\end{abstract}

Keywords: Teacher education. Science education. University-School.

1,3 Departamento de Matemática, Faculdade de Engenharia, Universidade Estadual Paulista Júlio de Mesquita Filho (Unesp). Avenida Brasil, 56, Centro. Ilha Solteira, SP, Brasil. 15.385-000.zulind@mat.feis.unesp.br

${ }^{2}$ Departamento de Física, Faculdade de Engenharia, Unesp, campus de Ilha Solteira. Ilha Solteira, SP, Brasil. 


\section{Introdução}

Este artigo apresenta parte dos resultados da pesquisa de doutorado da primeira autora, que dirigiu seu olhar para a formação do professor da universidade que atua em licenciaturas de Física, Biologia e Matemática, procurando compreendê-la a partir da participação desses sujeitos em um projeto de formação continuada de professores da rede pública de ensino, o projeto Urubunesp, realizado no período de 2002 a 2005 (FREITAS, 2008). Os sujeitos dessa pesquisa coordenavam grupos de trabalho, assumiam a orientação de pesquisas realizadas pelos professores da escola e participavam de reuniões gerais que envolviam outros professores da universidade e professores da escola. Assim, enquanto professora da universidade e participante do projeto, o olhar da pesquisadora voltou-se para uma dupla interação: entre professores da universidade e entre eles e os professores da Escola.

Nosso referencial teórico contempla as teorias de Pierre Bourdieu e Paulo Freire. Bourdieu forneceu-nos os conceitos que permitiram o aprofundamento na compreensão da escola como uma das instituições que trabalha afinada com uma lógica comum, que naturaliza as diferenças. Para Bourdieu (1997), os sujeitos/agentes colocam em prática um projeto de sociedade que aparece como "dado", isto é, que permite a experiência dóxica, quando tudo aparece como evidente e natural. Nesse âmbito, todo processo de transformação é assumido como prejudicial, pois, à medida que conduz ao questionamento do próprio projeto de sociedade, implica, sempre, risco de perda de capital econômico ou cultural. Buscamos, com esse autor, entender as contradições presentes nas estruturas de socialização. Além disso, ele nos ajudou tanto a ressaltar os elementos para um questionamento do caminho de naturalização do processo de socialização quanto a indagar sobre outras possíveis estruturas em construção que, porventura, caminhem para uma possível transformação. Paulo Freire e Ira Shor (2003) ajudaram-nos a compreender como as relações de poder, constitutivas do espaço social, podem ser direcionadas para a construção de conhecimento de maneira a tornar os sujeitos cada vez mais conscientes, autores e protagonistas dos seus processos e de sua história. Seus conceitos de "diálogo" e o "rigor metódico" nos auxiliaram, sobremaneira, na constituição de nossas categorias de análise.

Levando em conta esses referenciais, o nosso questionamento foi formulado do seguinte modo: em que condições podemos falar em formação docente para o professor universitário? Como a formação docente deste professor pode ser evidenciada durante sua participação em projetos como o Urubunesp? Assim, dirigimos nosso olhar para os formadores de professores, participantes do projeto Urubunesp, tentando entender como o seu envolvimento forneceu condições para sua formação para a docência.

\section{Espaço social e campo}

Para Bourdieu (1990), a representação do mundo social pelo agente, incluindo a do pesquisador, é realizada segundo a posição que o agente ocupa no espaço social. A constituição desse espaço leva em conta o acúmulo de capital econômico e de capital cultural. Essa distribuição espacial considera duas dimensões: a primeira é relacionada ao volume global de capital que os agentes possuem sob diferentes espécies, e a segunda leva em conta o peso relativo das diferentes espécies de capital, econômico e cultural, no volume global (BOURDIEU, 1990). 
Para Bourdieu (1983), as instituições de socialização apresentam, na sua estrutura, um sistema de classificação, de normas e de valores já determinados, produtos de lutas históricas anteriores, que são interiorizados pelos sujeitos na sua relação com esse ambiente. Os agentes fazem suas escolhas por meio de um sistema de classificação, segundo a posição (ditada pelo poder econômico e cultural) que ocupam no espaço social e segundo as chances percebidas de efetivá-las ou não. Essa adequação da realidade do sujeito à realidade objetiva lhe possibilita atuar de maneira natural, sem que isso seja percebido como produto de obediência explícita a regras, sem que nenhum cálculo consciente tenha sido realizado. Nesse sentido, a estrutura é a forma como as instituições de socialização são organizadas para produzir a adequação do indivíduo ao lugar, no espaço social. Por outro lado, os princípios dentro de uma organização são os fundamentos estabelecidos historicamente que dão origem à estrutura. Por meio das práticas sociais, presentes nesta última, os princípios são veiculados e incorporados pelos sujeitos como uma segunda natureza. Dessa maneira, a manutenção da estrutura passa pelo sujeito, que a compreende e a defende de maneira não consciente, como a única possível, e que não é determinada historicamente; assim, cada estrutura é estruturante.

Considerando que as práticas sociais são ações historicamente determinadas, os princípios são distribuídos e socializados através de diferentes estruturas, sendo tomados emprestados de estruturas antigas para as novas, uma vez que as referidas práticas se dão no mesmo espaço social, o que torna possível o surgimento de novas estruturas. Por outro lado, as normas, também presentes nas práticas sociais, não se confundem com os princípios, mas representam as investidas, as respostas dos sujeitos, e, nesse sentido, o diálogo deles com as estruturas; é dessa maneira participativa que os sujeitos têm a sensação de pertencimento ao grupo social. Nessas investidas, o sujeito age conformando seus valores e escolhas ao que está posto, não levando em conta que a própria realidade é produto de lutas históricas anteriores. Apropriando-se como sujeito conhecedor do que está posto, ele tem a sensação ilusória e libertadora de que cabe a ele o controle do porvir, como sujeito ativo/passivo da história.

Ao valorizar o papel estruturante da estrutura, estamos interessados em captar os princípios da organização social que irão provocar certas identificações que são percebidas como naturais. Isto requer a observação do conjunto de relações compartilhadas nessas estruturas: família, escola, política etc. Assim, a dificuldade da problematização tem como pontochave compreender e colocar em cheque os princípios que sustentam uma organização. Essa problematização não é função da instituição socializadora, posto que poria em risco a sua própria manutenção.

O campo é o elo de ligação entre o contexto social histórico e o conteúdo do que é produzido. Para Bourdieu (1997), cada campo é mais ou menos autônomo, em função da capacidade dos agentes de isolar determinações externas, transformando-as de maneira a privilegiar as questões que são próprias e interessantes ao grupo. Todos os campos (microcosmo), de maneira mais ou menos autônoma, estão submetidos a um universo maior (macrocosmo) no Campo e no Espaço Social.

Para o autor, existem tantos campos quanto são os grupos reunidos em torno de interesses específicos. Cada campo mantém-se por meio de estratégias de autovalorização, visíveis aos outros campos. O campo científico, no qual estamos interessados, é considerado, pelo autor, com suas relações de força e monopólios, suas lutas e estratégias, seus interesses e lucros, mas onde todas essas invariantes revestem formas específicas (BOURDIEU, 1997). O 
tipo de interesse que está em jogo nesse campo é o monopólio da autoridade científica, o poder simbólico, relacionado às capacidades técnicas de falar e de agir de forma legítima (autorizada e com autoridade), que é concedida a um agente por um ato de reconhecimento do grupo.

A visibilidade manifestada por meio do que é produzido e do capital acumulado em um campo, nem sempre é tangível. Considerando os dois campos, científico e escolar, podemos dizer que, no primeiro, a visibilidade concretiza-se nas obras produzidas. Nesse caso, podemos observar que a obra pode ser desligada do produtor. Diferentemente, no campo escolar, onde o acúmulo de capital não é tangível e só pode ser materializado através do diploma, observa-se uma indissociabilidade entre a obra e o produtor, o que acarreta uma dificuldade de atribuir valor. Isso faz com que o campo escolar fique menos visível, e, à medida que as críticas não são filtradas, mais sujeito às determinações externas. Os agentes, nesse caso, não se percebem como produtores de algo que tem valor e, nem mesmo, o reconhecimento dos pares é suficiente para a valoração, o que torna as disputas no espaço social fragilizadas.

\section{Crítica e transformação}

Dependendo da relação que o professor mantém com o conhecimento, sua prática colabora ou não para a manutenção do status quo (FREIRE; SHOR, 2003). No caso de uma prática que caminha no sentido de transformação da sociedade, o professor assume o dever de contestar a ordem estabelecida, não no sentido de manipulação e, menos ainda, de dominação, mas no sentido de aproximar, cada vez mais, o aluno, juntamente com o professor, da intimidade, da complexidade da teia de relações, da razão de ser do objeto em estudo. Conforme Freire e Shor (2003), a aula libertadora trabalha no sentido de desvelar a falsa liberdade presente nos mitos, no sentido de uma maior compreensão da realidade.

Dado que a ideologia dominante se expressa em instâncias externas e internas ao sujeito e que elas dizem respeito a expectativas internas de alcançar êxitos já determinados pela ordem estabelecida, torna-se responsabilidade do professor, que faz uma opção pela transformação, trabalhar favoravelmente tanto para que os sujeitos sejam bem-sucedidos na estrutura como para perceberem as ideologias introduzidas nas expectativas e as contradições nela existente (FREIRE; SHOR, 2003). Nessa perspectiva, a tarefa do professor nas escolas e instituições de Ensino Superior é a de discutir o próprio processo da educação, o que passa por incentivar a curiosidade e o rigor dos alunos, não garantindo, mas permitindo que estes percebam as contradições existentes na sociedade, possibilitando, com isso, que alguns continuem de maneira mais comprometida nesse processo de transformação.

Nessa prática, o diálogo é a confirmação conjunta do professor e dos alunos no ato comum de conhecer e reconhecer o objeto. Assim sendo, o diálogo requer uma aproximação dinâmica na direção do objeto, quando, então, o conhecimento não pode ser pensado como uma transferência estática de algo que está em princípio de posse do professor. Isso não significa não compartilhar algumas "certezas", mas sim vinculá-las à historicidade da ciência, ou seja, considerar que as perguntas surgem e adquirem sentido de acordo com a sociedade e o momento em que vivemos. Assim, um conhecimento novo surge e é substituído quando não dá conta de responder às questões que estão sendo feitas naquele tempo e lugar (FREIRE; SHOR, 2003). 
Com base nos nossos referenciais, trabalhar favoravelmente em direção a uma prática dialógico-libertadora exige compromisso por parte dos professores da universidade em construir conjuntamente com os professores da Escola a docência como valor, como algo de disputa no campo. Isso implica que esse algo não se resume apenas ao que é considerado isoladamente pela Universidade ou pela Escola, mas requer trazer para a mesa de discussão o valor que é dado à docência, em cada campo. Para que isso aconteça é necessário "rigor metódico", que, segundo Freire (1998), é inerente à produção de conhecimento, prática de pesquisa, permitindo objetivar a prática docente e, consequentemente, a construção da crítica com base na investigação. Nesse sentido, o professor pode referenciar sua prática diferenciando-a de um fazer ingênuo. Para Paulo Freire (1998), o ensinar exige rigorosidade metódica.

O educador democrático não pode negar-se o dever de, na sua prática docente, reforçar a capacidade crítica do educando, sua curiosidade, sua insubmissão. Uma de suas tarefas primordiais é trabalhar com os educandos a rigorosidade metódica com que devem se "aproximar" dos objetos cognoscíveis. (FREIRE, 1998, p. 28)

O professor que pensa certo deixa transparecer aos educandos que uma das bonitezas de nossa maneira de estar no mundo e com o mundo, como seres históricos, é a capacidade de, intervindo no mundo, conhecer o mundo. [...] Daí que seja tão fundamental conhecer o conhecimento existente quanto saber que estamos abertos e aptos a produção do conhecimento ainda não existente. Ensinar, aprender e pesquisar lidam com esses dois momentos do ciclo gnosiológico: o em que se ensina e se aprende o conhecimento existente e o em que se trabalha a produção do conhecimento ainda não existente. A "do-discência" e a pesquisa, indicotomizáveis, são assim práticas requeridas por estes momentos do ciclo gnosiológico. (FREIRE, 1998, p. 31)

\section{Metodologia de pesquisa}

A parceria universidade-escola começou no início do ano 2000 e seguiu, interruptamente, até o final de 2005, podendo ser dividida em duas grandes fases. Na primeira, realizamos encontros semanais com todos os professores da escola, nos horários de trabalho coletivo da escola. A equipe da universidade era então composta por oito docentes e uma pós-graduanda em Educação para a Ciência. Nesses encontros, foram conduzidos estudos de textos sobre avaliação formativa e trabalho colaborativo, e foram realizadas discussões sobre os interesses envolvidos na parceria.

Na segunda fase, iniciada em agosto de 2002, o projeto foi intitulado, "A implementação da avaliação formativa numa escola pública", passando a ser financiado pela Fundação de Amparo à Pesquisa do Estado de São Paulo (FAPESP), dentro do Programa de Melhoria do Ensino Público. Distinguimos, nela, três períodos. No primeiro, os integrantes dos dois segmentos fixaram-se em quatro pequenos grupos, que se encontravam semanalmente, crian- 
do "interesses" e sinais de "distinção" próprios. No segundo, o "interesse" do "grupão" pôde ser visualizado por meio de: encontros gerais para apresentação de trabalhos dos integrantes dos pequenos grupos; assembleias, e um ciclo de seminários sobre textos estudados, que era realizado na escola, para todos os professores, no seu horário de trabalho coletivo. Por fim, no terceiro, houve ampliação do número de pequenos grupos e manutenção dos vários tipos de encontros, sendo também propostos e realizados dois simpósios regionais, que envolveram professores de outras escolas de Ensino Básico e pesquisadores na área de Educação.

Nossos dados foram coletados durante o sexto ano do projeto. Durante esse ano inteiro, a primeira autora acompanhou sistematicamente os encontros de três grupos, que foram escolhidos porque seus coordenadores (ou, pelo menos, um deles) pesquisavam em áreas de Ciências Naturais ou Matemática, não sendo vinculados formalmente à pesquisa em Educação. Assim, o foco estava nos coordenadores, chamados aqui de AON, MEL e de ACA, que coordenavam diferentes Pequenos Grupos de Pesquisa (PGP).

O primeiro grupo era coordenado por duas pesquisadoras em Educação Científica e por um pesquisador em Matemática (AON). Dele participavam, também, dez professores bolsistas, que atuavam em diferentes áreas do conhecimento. Embora os temas das pesquisas dos professores estivessem expressos nos projetos individuais, os coordenadores esperavam que eles fossem entendidos como sugestões que possibilitariam uma indagação e uma procura, de modo a oportunizar a expressão das individualidades e a busca incessante por um ponto de vista comum. Ao se lançar nesse processo coletivo/individual de busca, o grupo acabou por ultrapassar o foco de atenção inicial do projeto (a avaliação na sala de aula), contemplando temas gerais, tais como: a reflexão do professor sobre o seu trabalho em sala de aula, sua profissão, a colaboração na escola e a parceria com a universidade.

O segundo grupo, coordenado por uma pesquisadora em Biologia (MEL) e um pesquisador em Física, organizou os trabalhos individuais de dois professores de Biologia e uma de Física em torno do tema a "Avaliação formativa na sala de aula de ciências e nos laboratórios didáticos de física e de biologia". Nesse contexto, os professores foram convidados a fazer dois tipos de reflexão: compreender melhor o que significa implementar a avaliação formativa em aulas de ciências e buscar práticas de sala de aula e de laboratório que levassem em consideração uma troca de feedbacks mais intensa e de maior qualidade (ORQUIZA-DECARVALHO, 2005b).

O terceiro grupo passou a existir no ano de 2004, constituindo-se a partir da fusão de outros dois, sendo, agora, coordenado por uma professora de Química, ACA. Anteriormente, ACA tinha coordenado um grupo com foco no laboratório de Química e em um projeto de grupo de ciências. O outro grupo que agora compunha a fusão desenvolvia trabalhos individuais em torno de um grande tema central - os impactos socioambientais causados por uma construção de uma usina hidrelétrica de grande porte (Usina Hidrelétrica de Ilha Solteira) -, cuja característica interdisciplinar permitia ser olhado sob as perspectivas de professores de diferentes áreas do conhecimento. Assim sendo, esse grupo continuou com os mesmos projetos, e era composto por seis professores bolsistas de diferentes áreas do conhecimento.

Além da utilização dos registros dos encontros dos pequenos grupos, baseamo-nos, também, nos registros dos encontros gerais de apresentação de trabalho e em entrevistas realizadas pela coordenadora geral. Foram também utilizados os relatórios anuais e a proposta do projeto, apresentados ao órgão financiador. As gravações foram transcritas, algumas pela 
Educação de professores da universidade ...

primeira autora deste artigo, e outras, por uma secretária que conhecia bastante bem todos os integrantes do projeto. A nossa análise foi constituída considerando-se o conjunto total de registros e desenvolvida conforme Bardin (1988).

\section{Análise}

Procuramos evidenciar os princípios que sustentavam a parceria, baseando-nos nos registros relativos à proposta do projeto e aos encontros realizados. Dessa maneira, pudemos revelar características que nos permitiram argumentar sobre como o projeto contribuiu para a formação docente.

\section{Os princípios}

Dirigindo o nosso olhar para as diversas práticas do projeto, reconhecemos, nele, dois princípios: interdisciplinaridade e autoavaliação.

\section{O princípio da interdisciplinaridade}

O projeto caracterizou-se sempre como uma proposta de dupla interdisciplinaridade. A primeira refere-se ao envolvimento de todos os professores da escola, e não apenas àqueles cuja matéria a ser ensinada definia-se dentro de áreas próprias do conhecimento científico. $\mathrm{O}$ fato aqui relevante é o de que, na perspectiva de AON, MEL e ACA, esse ambiente aparecia como não natural, uma vez que estavam acostumados a atuar somente em situações nas quais as áreas de conhecimento eram bem definidas. Justamente por isso, a sua autoridade nessas áreas era de antemão reconhecida, quer seja na pesquisa e nas salas de aula da universidade, quer seja na condução de cursos de formação continuada de professores. A segunda refere-se ao fato de que, no seu conjunto, os professores da universidade do projeto tinham diferentes tipos de formação em pesquisa (Educação para a Ciência, Matemática, Biologia e Química). Enfatizamos a novidade e o privilégio que consistiu o seu enfrentamento de barreiras interdisciplinares, uma vez que tiveram, por um lado, oportunidade de interação maior entre si com relação ao que normalmente ocorre na vida universitária, e, por outro, grande interação com professores da escola básica que atuam em diferentes áreas.

O termo "pesquisa do professor" representou o denominador comum para as interações interdisciplinares. Alguns elementos necessários para desencadear esse processo se apresentavam, para o professor da universidade, no limiar entre o conforto da sua pesquisa original e o desconforto da pesquisa dirigida para pensar a Escola como um todo. Na perspectiva de Bourdieu (1997), a construção do conhecimento está associada a valores a que tanto o professor da universidade como o professor da escola estão submetidos. Na proposta do projeto a construção do conhecimento era veiculada pela aposta na "pesquisa do professor", fato que carregava ambiguidade. Se, por um lado, a pesquisa, de um modo geral, é um dos valores da universidade, por outro, enquanto produção de conhecimento valorada pelos professores da universidade, não está necessariamente associada a sua atividade de ensino e, de fato, na maioria das vezes, isso não aconteceu. Segundo Carvalho (2005b), é justamente a imprecisão da expressão "pesquisa do professor" que permitiu com que ela fosse, de alguma forma, acessada tanto pelo professor da escola como pelo pesquisador da universidade. As- 
sim, ao aceitarem o convite, os professores da universidade tiveram de projetar suas próprias expectativas sobre esse objeto difuso de conhecimento: a docência.

De fato, nas análises realizadas, destacamos diferenças substanciais no que se refere às expressões do professor da universidade a respeito de sua prática docente, observadas a partir do rigor metódico veiculado no projeto pela pesquisa do professor. Essa pesquisa facilitou para que os docentes trouxessem algo que lhes era familiar em uma situação nova, tornando, assim, possível para eles distinguir elementos que permitiram a sua formação docente. Assim, a produção de conhecimento sobre a docência revelou-se sempre balizada pelo valor a ela atribuído pelo professor da universidade, estando diretamente vinculada tanto ao investimento possível, realizado por ele, como à sua formação - essa valorização da docência não é dependente apenas de sua vontade própria, mas também da estrutura do subcampo a que ele está submetido.

Assim, MEL apoiou-se fortemente na literatura na área de Educação, investindo para que os seus orientandos-professores se apropriassem dela. ACA, por sua vez, apoiou-se no saber adquirido, durante sua formação de pesquisadora na área própria, e no exercício da atividade docente nessa área, investindo, através da fala, na troca de informações com os seus orientandos-professores, para que eles se organizassem na apresentação do problema a ser conduzido. Por fim, AON apoiou-se no rigor do processo argumentativo, investindo na construção, compartilhada com seu orientando-professor, de um objeto pedagógico comum.

Consideramos que a rigorosidade está presente nas ações de MEL e ACA, o que significa que elas ultrapassaram o plano do fazer. Consideramos também que a rigorosidade tornou-se possível porque o modo de produção da ciência foi por elas recuperado. No entanto, embora possamos considerar a rigorosidade como sinal que caracteriza e atribui valor à produção docente, baseando-nos em Freire (1987), percebemos que ela não é suficiente. Assim, ao dirigirmos o nosso olhar para $\mathrm{AON}$, observamos indícios não somente de rigorosidade, mas, também, de dialogicidade, o que lhe permitiu, na interação com professor da escola, a construção de um objeto de conhecimento comum. Pudemos notar também que, por meio do diálogo rigoroso, houve, enfim, suspensão da hierarquia entre os sujeitos envolvidos, sendo que o foco esteve no reconhecimento do direito e da necessidade da fala de ambas as partes.

Abordando particularmente o caso de MEL, entendemos que a apropriação das teorias da educação já se constitui como posse de uma ferramenta importante nas mãos dos professores, tendo em vista que, normalmente, eles se encontram cultural e economicamente distantes da possibilidade de produção científica, legitimada e valorada pela universidade. Uma vez tendo se familiarizado com tais teorias educacionais, os dois tipos de professores, da Escola ou da Academia, podem falar de suas ações com mais segurança, visto que encontram algum apoio para referenciá-las.

Diferentemente do caso de MEL, ACA utilizou todas as ferramentas possíveis para garantir o rigor na relação de orientação, tanto por suas razões da prática profissional como pelo que adquiriu durante sua formação como pesquisadora. Isso foi a única garantia possível do seu compromisso com o projeto e com os professores da escola. De fato, ela lançou-se em diferentes desafios. Ao atuar enquanto coordenadora de PGP, explicitou seus "saberes" referentes à atividade de ensinar/aprender. Enquanto orientadora, teve a pretensão de garantir o máximo rigor possível, organizando e apresentando, de maneira mais objetiva, o problema a ser conduzido pela professora. Enquanto membro ativo e participante dos encontros gerais de apresentação de trabalho, interagiu com pesquisadores de diferentes áreas, procurando se fa- 
miliarizar com a literatura da área de educação, buscando novas metodologias e novas formas de condução dos problemas. Reciprocamente, foi solicitada pelos professores e respondeu trazendo todas as ferramentas possíveis. Participou, também, das decisões referentes aos rumos do projeto, assumindo a responsabilidade de manter o dinamismo que garante a sua estrutura. No entanto, embora sua participação fosse incondicional, estava sujeita aos limites relativos à própria disposição e ao capital legitimado na estrutura a que estava sujeita. Entendemos que o sentimento individual e coletivo de culpa, alcançado pela estrutura como estruturante, não favoreceu, no caso de ACA, transgressões aos limites estabelecidos pelo campo.

Nossos resultados nos permitem, ainda, fazer considerações sobre a relação do professor da universidade com os seus saberes, considerando que os saberes do professor constituem a base que sustenta a sua prática. Os saberes de ACA, explicitados durante as várias atividades, trouxeram sempre vestígios de sua formação enquanto pesquisadora. Apoiados em Tardif (2002), defendemos que é preciso que os saberes dos professores da universidade sejam trazidos à baila para serem debatidos, par a par, com o estudo das teorias educacionais, o que então permitirá a criação de uma nova perspectiva de compreender e abordar a realidade. Defendemos que a participação dos professores da universidade no projeto constituiu uma situação favorável para isso.

Neste momento, nosso intuito é chamar a atenção para a desvalorização atual do professor da universidade enquanto profissional do ensino, nas licenciaturas. Defendemos que ele esteja em formação e que essa formação considere seus saberes (TARDIF, 2002), os quais se diferenciam dos saberes dos professores da escola pela ferramenta da argumentação que os sustenta, advinda da sua vivência na formação de pesquisador e, por meio dessa ferramenta, organiza os saberes da prática apoiados na racionalidade técnica (SCHÖN, 2000), o que lhes confere maior poder de convencimento.

\section{O princípio da autoavaliação}

Esse princípio permitia que os investimentos individuais a serem realizados e o seu modo de condução fossem matéria de foro subjetivo. Isso significa que os professores da universidade e professores da escola eram os responsáveis por decidir quanto e como iriam se envolver e abraçar o projeto. Isso pôde ser percebido durante um encontro geral de apresentações dos trabalhos individuais, quando o professor da universidade WAS, um pesquisador em Educação para a Ciência, chamou MEL, implicitamente, para ser mais rigorosa no tocante à metodologia científica da pesquisa em educação científica, mas deixou, exclusivamente, a MEL a decisão de como e quanto iria investir na investigação em educação científica, que ela estava conduzindo junto com o professor da escola.

Dessa forma, entendemos que a autoavaliação é um dos eixos que possibilitam a transformação. De fato, a ideia da transformação que utilizamos é a de que é uma decisão individual que está, porém, ligada à estrutura e à percepção do sujeito da estrutura a que está submetido. Assim, para nós, a ideia de formação está associada à ideia de transformação, isto é, quando nos sentimos questionados em nossas certezas, temos a chance de restabelecermos uma nova leitura daquilo e sobre aquilo que assumimos anteriormente como dado (CHAUÍ, 2001; FREIRE; SHOR, 2003).

O princípio da autoavaliação implica a previsão de atividades que possibilitem ao professor da universidade se apropriar, de maneira cada vez mais consciente, do processo de 
condução da sua ação. Nesse sentido, compreender a base que sustenta a razão prática do professor da universidade se torna fundamental, uma vez que o projeto previa estruturas que poderiam desestabilizar os professores da universidade quanto à segurança de suas verdades e, ao mesmo tempo, atribuir a ele a responsabilidade de trilhar e escolher o seu próprio caminho. Assim, no período de consolidação dos PGP, a ideia de como cada um dos professores da universidade exercia sua autonomia passou a ser fundamental para a coesão das ações conjuntas, fazendo com que se tornasse relevante, para ele, compreender quais eram os elementos presentes.

Assim, ao reconhecer as preocupações de um professor da escola como legítimas, AON investiu no diálogo como construção do conhecimento. Nesse espaço, questões centrais relacionadas à prática do professor da escola foram explicitadas. Ambos estabeleceram e compartilharam uma regra implícita para a construção do conhecimento: o rigor nas colocações. Essa exigência de AON, para que o professor compusesse com mais elementos a sua problemática, mostrou-se envolvente, também, para os demais integrantes de seu grupo, o que se deu, também, pela abrangência desse modo de proceder, que encontrava ressonância com instâncias mais gerais do projeto. Podemos dizer que os encontros semanais, no PGP, permitiam a AON explicitar o próprio capital cultural acumulado, que era reconhecido pelo professor da escola e por ele utilizado para reelaborar questões mais gerais referentes à Escola. Esse capital cultural se convertia em crédito divergente (FREIRE; SHOR, 2003), possibilitando a AON ter a sua posição própria reconhecida, também, na relação com os pesquisadores de Educação Científica. Entendemos que a obtenção desse crédito foi importante, visto que houve possibilidade de se estabelecer, a partir daí, um diálogo (FREIRE, 1987) entre pesquisadores de áreas distintas e com professores da escola que atuavam em disciplinas diferentes.

\section{Considerações finais}

Neste trabalho, pudemos vincular a perspectiva epistemológica com a estrutura, propondo que a oportunidade de orientar a "pesquisa do professor" foi determinante para que os professores da universidade se aproximassem da docência enquanto um objeto de conhecimento. Isso ocorreu à medida que essa atividade acabou se configurando como oportunidade de expressão do rigor metódico, trazido do seu campo de origem, no contexto da prática docente. De fato, ao se relacionar com os professores da escola de forma mediada pela "pesquisa do professor", a primeira preocupação do professor da universidade era justamente a de compartilhar o rigor metódico visando permitir que o primeiro problematizasse a sua prática docente, tendo em vista que esta é o objeto da pesquisa do professor. Em contrapartida, o professor da escola lhe devolvia construções que o levavam para um lugar inusitado, fazendo com que ele passasse, então, a refletir sobre sua própria prática docente. Desse modo, a possibilidade de compreender, também, a sua docência com um rigor metódico, e não somente a sua pesquisa, possibilitava a ele a posse de instrumentos de compreensão e transformação da práxis.

Assim, o fato de o professor da universidade buscar elementos teóricos e da prática para, juntamente com o professor da escola, viver a experiência de construir a docência como valor, representa um distanciamento do campo de origem, à medida que foi levado a mergulhar em um problema não considerado como valor no seu campo. Essa experiência se distin- 
gue da experiência de pesquisador e professor, na qual os sujeitos necessitam - até para o reconhecimento na área própria de conhecimento - de um mergulho nos problemas já considerados relevantes no campo.

Reconhecemos que os propósitos da "pesquisa do professor" não são veiculados apenas pelas boas intenções dos que se propõem a orientá-las, mas pelas estruturas a que eles estão sujeitos. Isso está parcialmente de acordo com Zeichner e Diniz-Pereira (2005) e com CochranSmith e Lytle (1999), que entendem que a pesquisa do professor pode servir a diferentes propósitos e interesses, independentemente da boa vontade do professor da universidade. Embora tais autores considerem que as concepções que embasam tais movimentos se relacionam com o compromisso assumido frente ao ensinar e aprender, e assim, com a sociedade, não ressaltam que há disputas sendo travadas, por trás das diferentes visões de mundo neles subentendidas. Assim sendo, qualquer pretensão de "colaboração" entre esses movimentos (ZEICHNER; DINIZ-PEREIRA, 2005) não ocorre senão enquanto transgressão à ordem estabelecida, o que precisa ser encarado como um desafio. Concluímos que, por não ser natural, essa colaboração exige ser paulatinamente construída em um espaço que tenha como desafio lidar com as diferenças de "campos". Nesse sentido, ressaltando a importância de lidarmos com desafios intercampos, concordamos com Cochran-Smith e Lytle (1999), que, por um lado, chamam nossa atenção para o universo de possibilidades que a pesquisa nos oferece, servindo a diferentes agendas, e, por outro, nos alertam que seria indesejável que essa natureza proativa da pesquisa, que evoca um estado de atividade criadora, conduzisse à marginalização, trivialização, colonização ou cooptação, servindo a projetos impostos e externos à Escola.

A formação evidenciada por meio dos princípios da interdisciplinaridade e autoavaliação possibilita a crítica ao instituído, que não se realiza de maneira isolada, sem que haja apropriação de uma cultura geral e sem que o sujeito assuma compromisso individual e coletivo (CHAUÍ, 2001). A nossa pesquisa, em busca da explicitação dessa formação, ocorreu por meio de uma proposta de trabalho que privilegiava a Escola, enquanto possibilidade de diálogo com a cultura geral, o qual permitiu que todos, professores da universidade e professores da escola, se sentissem desafiados. Por outro lado., enquanto um espaço intercampos, o projeto possibilitou, aos professores da universidade (mediante o diálogo, a literatura, o saber do pesquisador), entenderem os limites e os condicionantes de sua ação, trazendo à tona sua individualidade, o que implicava respeitar seu próprio tempo e seu grau de compromisso para com o projeto. Além disso, a participação deles nos vários fóruns, nos quais dialogava com professores da escola, de todas as disciplinas, e professores da universidade, pesquisadores em áreas próprias do conhecimento, permitia que o dinamismo dos arranjos do projeto fosse sempre reavaliado, o que colaborava para que o ambiente permanecesse provocador e formativo.

\section{Referências}

BARDIN, L. Análise de conteúdo. Lisboa: Edições 70, 1988.

BOURDIEU, P. Esboço de uma teoria da prática: sociologia. In: ORTIZ, R. (Org.). Pierre Bourdieu: sociologia. São Paulo: Ática, 1983. p. 46-81. 
Freitas, Z. L.; Carvalho, L. M. O.; Oliveira, E. R.

BOURDIEU, P. Aberturas. In: Coisas ditas. São Paulo: Brasiliense, 1990. p. 149228.

Os usos sociais da ciência: por uma sociologia clínica do campo científico. São Paulo: Editora Unesp, 1997.

Razões práticas: sobre a teoria da ação. Campinas: Papirus, 2004.

CARVALHO, L. M. O. de. Relatório final de projeto: a prática da avaliação formativa em uma escola pública. São Paulo: FAFESP, 2005a.

A educação de professores como formação cultural: a constituição de um espaço de formação na interface entre a universidade e a escola. 2005. Tese (Livre-docência) - Universidade Estadual Paulista, Ilha Solteira, 2005b.

CARVALHO, L. M. O. de.; MARTINEZ, C. L. P.; OLIVEIRA, E. R. A autonomia do grupo de orientação e planejamento de um projeto de interação universidade/escola. In: ENCONTRO NACIONAL DE PESQUISA EM EDUCAÇÃO EM CIÊNCIAS, 2007, Florianópolis. Anais... Florianópolis: ABRAPEC, 2007. p. 84.

CHAUÍ, M. Escritos sobre a universidade. São Paulo: Editora Unesp, 2001.

COCHRAN-SMITH, M.; LYTLE, S. L. The teacher research movement: a decade later. Educational Researcher, Washington, v. 28, n. 7, p. 15-25, 1999.

CUNHA, M. I.; LEITE, D. B. Decisões pedagógicas e estruturas de poder na universidade. Campinas: Papirus, 1996. (Coleção magistério: formação e trabalho pedagógico).

FREITAS, Z. L. Um projeto de interação universidade-escola como espaço formativo para a docência do professor universitário. 2008. 140 f. Tese (Doutorado em Educação para a Ciência) - Faculdade de Ciências, Universidade Estadual Paulista, Bauru, 2008.

FREIRE, P. Pedagogia do oprimido. Rio de Janeiro: Paz e Terra, 1987.

Pedagogia da autonomia. Rio de Janeiro: Paz e Terra, 1998.

Educação como prática da liberdade. Rio de Janeiro: Paz e Terra, 2000.

FREIRE, P.; SHOR, I. Medo e ousadia: o cotidiano do professor. 10. ed. São Paulo: Paz e Terra, 2003. (Coleção Educação e Comunicação, v. 18).

SCHÖN, D. A. Educando o profissional reflexivo. Porto Alegre: Artes Médicas, 2000.

TARDIF, M. Saberes docentes e formação profissional. Petrópolis: Vozes, 2002.

ZEICHNER, K. M.; DINIZ-PEREIRA, J. E. Pesquisa dos educadores e formação docente voltada para a transformação social. Cadernos de Pesquisa, São Paulo, v. 35, n. 125, p. 63-80, 2005.

Artigo recebido em 03/08/2011. Aceito em 29/01/2012. 